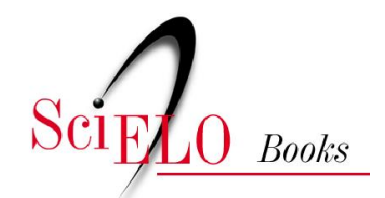

\title{
Capital social e desenvolvimento no submédio São Francisco
}

\author{
Gilton Carlos Anísio de Albuquerque \\ Gesinaldo Ataíde Cândido
}

\section{SciELO Books / SciELO Livros / SciELO Libros}

ALBUQUERQUE, GCA., and CÂNDIDO, GA. Capital social e desenvolvimento no submédio São Francisco. In: LIRA, WS., and CÂNDIDO, GA., orgs. Gestão sustentável dos recursos naturais: uma abordagem participativa [online]. Campina Grande: EDUEPB, 2013, pp. 123-147. ISBN 9788578792824. Available from SciELO Books $<$ http://books.scielo.org $>$

\section{@)(1)(9)}

All the contents of this work, except where otherwise noted, is licensed under a Creative Commons Attribution-Non Commercial-ShareAlike 3.0 Unported.

Todo o conteúdo deste trabalho, exceto quando houver ressalva, é publicado sob a licença Creative Commons Atribuição Uso Não Comercial - Partilha nos Mesmos Termos 3.0 Não adaptada.

Todo el contenido de esta obra, excepto donde se indique lo contrario, está bajo licencia de la licencia Creative Commons Reconocimento-NoComercial-CompartirIgual 3.0 Unported. 


\title{
Capital social e desenvolvimento no submédio São Francisco
}

\author{
Gilton Carlos Anísio de Albuquerque
}

Gesinaldo Ataíde Cândido

\section{Introdução}

O caráter complexo que caracteriza a realidade das últimas décadas do século passado e início do século XXI tem permitindo o reconhecimento de um conjunto de novos processos, noções e conceitos no campo do desenvolvimento, com surgimento e uso de novas linguagens que são produtos e produtoras de ações, significados e representações. O despertar para a sustentabilidade multidimensional dos sistemas e o paradigma da interdisciplinaridade científica, a acelerada produção tecnológica em contraste com a tendente desaceleração de ritmos de vida na Europa, a revalorização da ética, a relativização da economia na escala hierárquica da qualidade de vida, a responsabilidade social dos empreendimentos, entre outras questões, têm permitido o surgimento de novos caminhos rumo a novos parâmetros de eficácia das ações sociais e com isso, gerando novos discursos, sociabilidades e compreensões em nível de sociedade como um todo.

Embora tardiamente, em comparação aos estudos sobre o tema nos países desenvolvidos, a expressão "agricultura familiar" veio à tona no Brasil, nesse período, em função de três acontecimentos simultâneos: a adoção da expressão pelos movimentos sociais como categoria síntese, dando guarida a um conjunto de categorias como assentado, 
arrendatário, parceiro, etc.; a legitimação emprestada pelo Estado na criação do PRONAF, em 1996, e a reorientação dos debates em torno dos estudos agrários (SCHNEIDER, 2006).

Tal contexto extrapolou o debate prevalecente em torno da reforma agrária e tem avançado para outras perspectivas teóricas em torno desses atores sociais no processo de desenvolvimento, favorecendo análises que explicam os determinantes que permitem a reprodução da agricultura familiar no capitalismo pós-industrial e sua importância aos preceitos da sustentabilidade.

Sabourin, (2000), tratando das estratégias da viabilidade da agricultura familiar, diz que num território estabelecem-se relações de comunicação interpessoal ou de proximidade, relações socioeconômicas de solidariedade ou de reciprocidade entre as famílias e também novas formas locais de coordenação entre os produtores: as organizações profissionais como sindicatos, associações, cooperativas e as redes interpessoais como as de comercialização ou as redes de inovação.

Quanto a isso, cabe ressaltar que foi também, no final da década de 90 do século passado, que a literatura passou a enfatizar o papel das instituições e organizações diversas no processo de desenvolvimento, incorporando o termo "capital social" como indicador e atributo a somar-se com os tradicionais capitais: humanos, financeiros, naturais e físicos, que materializados, explicam a possibilidade de sua acumulação, a qual, até determinados limites, promove a sustentabilidade.

Intimamente relacionado à capacidade de organização e institucionalização de redes sociais de cooperação, o capital social é uma argamassa que dá sustentação através de laços de confiança, reciprocidade, normas e costumes, mantendo-as coesas, visando à produção do bem comum. (COLEMAN, 1998; PUTNAM, 1993; PORTES, 1998; BOURDIEU, 1985, apud NOVAES, 2005).

Segundo Abramovay (1998) e Beduchi e Abramovay (2004), a capacidade dos atores de estabelecer relações organizadas - mercantis e não mercantis - é o que favorece não só a troca de informações e a conquista conjunta de certos mercados, mas também pela existência de bens públicos e de administrações capazes de dinamizar a vida regional, sendo possível criar capital social ali onde ele não existe e que, no âmbito da agricultura familiar, os movimentos sociais, bem como a extensão rural têm papéis estratégicos, contribuindo para formação dos indivíduos, uma vez que a política territorial não deve consistir em redistribuição de 
recursos e riquezas já criadas e existentes, mas ao contrário, em despertar os potenciais para a sua criação através de iniciativas e coordenações por meio de organizações que sejam significativas para os atores locais, numa dimensão espacializada de conhecimentos tácitos com base nos quais, eles se relacionam mútua e coordenadamente, dando ênfase á ideia de capital social.

O objetivo deste artigo é contribuir para a reflexão em torno da importância dos temas capital social e desenvolvimento territorial, com foco na agricultura familiar dos perímetros irrigados do Vale do Submédio São Francisco, a partir de dois contextos distintos: 1. no qual, o Governo Federal assumiu o papel de agente de desenvolvimento e de organização do espaço, a partir dos anos 1960, através de um processo de colonização, no bojo das políticas setoriais desenvolvimentistas e 2. no processo de reassentamento de populações atingidas pela barragem de Itaparica, a partir do final dos anos 1980, cujo processo foi mediado pelo Movimento Social alicerçado nos Sindicatos dos Trabalhadores Rurais da região.

Em termos metodológicos, será analisado como a ação dos agentes externos tem interferido no processo de formação de capital social junto aos agricultores familiares dos referidos perímetros de irrigação, através de uma análise baseada em fontes de dados primários e secundários, lançando mão dos fundamentos teóricos do capital social e do desenvolvimento territorial com vista a uma releitura desses contextos específicos.

Além deste conteúdo introdutório, o artigo está estruturado em mais quatro itens: no segundo, apresenta-se uma fundamentação teórica acerca do capital social; do desenvolvimento territorial e de aspectos acerca das políticas de desenvolvimento baseadas na agricultura para o Vale do São Francisco. No terceiro, trata-se dos procedimentos metodológicos utilizados. No quarto item, são apresentados e analisados os resultados obtidos e, por fim, no item cinco, as conclusões do trabalho, seguidas da bibliografia utilizada.

\section{Fundamentação Teórica}

\section{O Capital Social}

O conceito de capital social, segundo Franco (2001), tornou-se importante a partir da década de 1990, porém a ideia em si não é nova, tendo sido Alexis de Tocqueville a primeira pessoa a descrever o fenômeno que o conceito de capital social quer captar. Entretanto, o conceito 
só foi elaborado de uma maneira mais completa pelos sociólogos Pierre Bourdieu e James Coleman, sendo este último quem introduziu a expressão no debate do desenvolvimento, no âmbito da sociologia já um pouco pautada pela economia. Nesse mesmo período, deram-se as contribuições de Robert Putnam e de alguns de seus críticos como Alejandro Portes, Everett Ladd, P. Evans e Francis Fukuyama.

Segundo Novaes (2005), duas grandes correntes teóricas são definidas nesse contexto, sendo uma focada nas relações entre atores sociais bem como na ideia de que suas ações podem ser fortemente enaltecidas, através de participação e do estabelecimento de interações em redes, tendo estas correntes como expoentes: Colemam, Bourdieu e Portes. A outra corrente entende capital social como uma parte significativa das relações e laços internos que caracterizam as bases da ação coletiva e lhe garante a coesão para atingir resultados esperados, sendo representada por Putnam, Locke e Fukuyama.

O mesmo autor define capital social como um conjunto de bens sociais, psicológicos, cognitivos e institucionais que possibilitam a produção de comportamento cooperativo mutuamente benéfico, porém ressalta a possibilidade para interpretações e conceitos diversos que permitem dividir, conforme a posição dos agentes envolvidos, em três categorias: comunitária, pontes e institucional, que nesta ordem associam capital social a organizações locais, grupos cívicos e redes informais; passando pela possibilidade dos grupos se interagirem com outros em outras realidades, até a capacidade de interferência que os grupos sociais têm sobre o governo e outras organizações formais.

Basicamente, o capital social liga-se ao estabelecimento de relações e seus padrões, de forma que, quanto mais relações horizontais se formarem entre pessoas e grupos de uma coletividade e quanto mais democráticos forem os processos políticos praticados, mais forte será a comunidade e maior será o nível do seu capital social (FRANCO, 2001).

Quanto às relações que se dão entre capital social e desenvolvimento, Durston $(1998 ; 2000)$ faz referência às normas, instituições e organizações que promovem a confiança, a ajuda recíproca e a cooperação entre as pessoas nas comunidades e sociedade em seu conjunto. As normas culturais de confiança e as redes interpessoais de reciprocidade são, pois, precursoras daquelas instituições mais complexas e orientadas por normas de bem-estar comum. 
Ainda Durston (1998; 2000), integrante da corrente teórica neo -institucionalista, o problema que Putnam nega aos leitores é o da construtibilidade do capital social, uma vez que atribui às diferenças entre o sul do norte da Itália ao contraste cultural - como medida de crescimento cívico regional - levando ao questionamento equivocado sobre as possibilidades das agências de desenvolvimento comprometerem recursos para promoverem o capital social.

Sobre esse prisma, Abramovay (1998) diz que o trabalho de Putnam é importante para mostrar que ali onde o capital social existe, ele é um elemento decisivo do desenvolvimento. Mas ele tem pouco a dizer quanto à pergunta: ele pode ser criado? Capital social não é simplesmente um atributo cultural cujas raízes só podem ser fincadas ao longo de muitas gerações, sua acumulação, ao contrário, dá-se mediante à criação de processos capazes de revelar os potenciais que os atores sociais podem descobrir em seus locais de vida.

Durston $(1998 ; 2000)$ afirma, ainda, que existe uma dupla função dos agentes externos na ação de intervenção: a) como provedores das metodologias disponíveis para que o capital social se desenvolva com rapidez e segurança investindo nas capacidades e habilidades das pessoas em negociar, gerenciar, comunicar, participar e mobilizar recursos; b) devem criar mecanismos de proteção frente a ações paternalistas e conservadoras, contrárias à mobilização de base comunitária.

Segundo Beduchi Filho e Abramovay (2004), a depender da capacidade criadora que a própria interação entre atores locais é capaz de conduzir, pode-se substituir as estruturas sociopolíticas piramidais por uma abordagem policêntrica, dotada de múltiplas instâncias de decisão em relação ao destino dos territórios, entendido como um locus que incorpora os aspectos econômicos, ambientais, sociais e culturais. A sua orientação, no entanto, vai depender do sentido de se conseguir o comprometimento dos cidadãos em se engajarem em uma ação de planejamento estratégico que seja permanentemente monitorada e envolva os diferentes atores, deixando de concentrar as decisões numa autoridade ou numa agência central encarregada de distribuir recursos.

Para Sabourin (1999), as formas de organização dos agricultores podem participar da reprodução ou da atualização de relações e estruturas econômicas e sociais de reciprocidade e nesse processo, o papel dos técnicos dos centros de desenvolvimento é, precisamente, contribuir para identificar e tornar mais visíveis e acessíveis as formas de inovação 
e os atributos específicos das sociedades locais, além de qualificar as relações de intermediação entre ação individual, ação coletiva e ação pública de maneira a poder desenhar e logo coordenar planos locais ou microrregionais de desenvolvimento territorial.

Com base nisto, deve-se considerar que o desenvolvimento territorial, enquanto conceito, já conta com aportes teóricos imprescindíveis ao contexto em análise, devendo assim ser resgatados visando a favorecer uma leitura mais adequada.

\section{O Desenvolvimento Territorial}

A compreensão do significado de território, na perspectiva do desenvolvimento, transcende às relações que dizem respeito unicamente ao espaço físico devendo ser entendido como uma construção social e política, constituindo-se por laços informais, por modalidades de interação construídas ao longo do tempo e que moldam uma certa personalidade, sendo uma das fontes da própria identidade dos indivíduos e dos grupos sociais. Em virtude da interação que os atores sociais promovem, no contexto territorial, eles constituem uma nova institucionalidade, fruto de uma construção coletiva onde se dá a concertação entre os atores sociais e os agentes públicos num novo sistema de governança (BEDUSCHI FILHO; ABRAMOVAY, 2004).

Colocado em prática e tendo como referência a União Europeia e os E.U.A, o desenvolvimento territorial é uma estratégia frente às evoluções recentes da economia internacional, emergindo como uma questão a ser aprofundada tanto nas economias do Norte quanto do Sul, significando que a justificativa de uma política de desenvolvimento territorial transcende a preocupação com o combate à pobreza e às desigualdades sociais.

Neste ínterim, cabe ressaltar que no caso brasileiro, tais processos foram contraditoriamente marcados pela postura intervencionista do Estado em relação ao território, preocupando forjá-lo, dotando-o de infraestruturas necessárias à ascensão econômica do país como um todo, e não é difícil afirmar que as diversas políticas de governo foram implantadas perseguindo a ocupação do espaço, através da colonização, construção de infraestrutura para modernização do território e viabilização da integração nacional, formulando planos nacionais de desenvolvimento (BECKER; EGLER, 1992; COSTA, 2001, apud COELHO NETO, 2009). 
Mediante uma postura centralizada, conformou-se, no país, um modelo caracteristicamente desenvolvimentista, que concentrava as decisões na escala do poder da União e que supervalorizava os elementos exógenos em detrimento das potencialidades locais. As políticas territoriais, até meados do século passado, foram pensadas e geridas por uma máquina governamental que ignorou o conhecimento e as aspirações das comunidades locais, concebendo e implantando ações numa perspectiva unilateral, amputando a participação de diversos segmentos da sociedade na condução das políticas públicas (COELHO NETO, 2009).

Tal cenário, porém, passou a modificar-se com o processo de redemocratização, legitimada pela Constituição de 1988, e as lutas políticas empreendidas pela sociedade civil. Os princípios democratizantes passaram então a influenciar a postura estatal e fazer emergir novos modos de condução das políticas descentralizadas ante a necessidade fundamental da participação da sociedade desde o planejamento até a execução das políticas governamentais, no sentido da democratização da gestão pública.

Não obstante à necessidade de um maior detalhamento da trajetória histórica das políticas de desenvolvimento rural, no Brasil, até chegar ao contexto da abordagem territorial mais recente, cabe ressaltar, por enquanto, que ela foi antecedida ainda na década de 90 passada, pela consolidação da agricultura familiar como categoria explicativa de uma determinada forma social de produção e sua definição como segmento prioritário para investimentos públicos, segundo Schneider et al (2003).

Tal abordagem se materializou na criação da Secretaria de Desenvolvimento Territorial (SDT) no Ministério do Desenvolvimento Agrário (MDA), cujo formato institucional para a implementação dos programas se traduziu em colegiados de desenvolvimento territorial, os quais se responsabilizam pela gestão das políticas e programas de desenvolvimento, representando importante novidade perante a trajetória histórica das políticas para o rural brasileiro, revelando-se, porém, ainda incapaz de encarnar a totalidade das forças vivas desses espaços, tendo abrangência de sua atuação restrita à agricultura, quando a ideia de desenvolvimento territorial pressupõe intersetorialidade (ABRAMOVAY 2003).

O Estado brasileiro que deveria ter papel decisivo para imprimir estabilidade e fornecer parâmetros de funcionamento da própria rede de iniciativas localizadas e voltadas à inovação no processo de 
desenvolvimento até hoje não rompeu com o caráter hierárquico de planejamento, herdado do governo militar, não o substituindo por um ambiente institucional desconcentrado para as atividades econômicas e fortalecimento de organizações no interior do País. (BEDUCHI FILHO; ABRAMOVAY, 2004).

Foi seguindo essa lógica que, segundo Barros e Tonneau (2004), ocorreram as transformações que foram implementadas pelo Estado no Vale do São Francisco com investimento em perímetros irrigados e na especialização da produção agrícola, visando ao crescimento econômico, através da busca exacerbada por eficiência e competitividade tentando transformar o agricultor familiar em "produtor empresário" sem ajudá-lo em suas capacidades, sem promover a reflexão específica sobre as vantagens comparativas entre agricultura familiar e empresarial como uma forma eficaz de complementação.

Embora considerado como mais justa socialmente, garantindo uma melhor distribuição de renda, a agricultura familiar, segundo Barros e Tonneau (2004), até os dias atuais, ela não tem uma posição definida no referido território, o que vem impedindo a consolidação de uma dinâmica de organização autônoma daqueles agricultores, dada a impropriedade das características das políticas de desenvolvimento regional, impróprias a esse intento, como será visto a seguir.

\section{As políticas de desenvolvimento baseadas na agricultura no Vale do São Francisco}

As iniciativas, em termos de política pública para desenvolvimento regional, só começaram a ser implementadas, no Vale do São Francisco, a partir do início do século XX, cabendo registrar a implantação de infraestruturas como a linha férrea ligando Juazeiro (BA) a Salvador, em 1927, e sua ampliação, anos depois, até a capital Teresina (PI) como uma das primeiras obras voltadas à integração regional. Com a criação do Instituto Federal de Obras Contra as Secas (IFOCS), posteriormente, Departamento de Obras Contra a Seca (DNOCS), veio a ocorrer a construção infraestruturas básicas como: estradas, poços, açudes e barragens, como também escolas e unidades de saúde. (CALDAS 2006).

Em 1946, é que efetivamente são definidos os recursos para desenvolvimento do Vale com a regulamentação da lei para aplicação de recursos do orçamento da República destinados a vários projetos e 
ações, dentre as quais se destacam as hidrelétricas de Paulo Afonso e de Sobradinho, barragens, rodovias, hospitais, linhas telegráficas, etc.

Para intensificar a determinação dessa prerrogativa, foram criados, em 1948, a Companhia Hidrelétrica do Vale do São Francisco - CHESF, para tratar da produção de energia elétrica e, com objetivo de fomento à agroindústria, a partir da irrigação, a Comissão do Vale do São Francisco (CVSF), hoje: Companhia de Desenvolvimento dos Vales do São Francisco e do Parnaíba - CODEVASF.

No que diz respeito à irrigação, segundo Andrade (1990), já em 1933, o Congresso Nacional discutiu a possibilidade de colonização do Vale do São Francisco, cujo debate resultou na definição da implantação de projetos de colônias agrícolas e, com essa premissa, foi instalado o Núcleo Colonial Agroindustrial São Francisco, através do Decreto Lei 4.505, publicado no DOU, em 24 de julho de 1942, no município de Petrolândia (PE), em pleno Semiárido nordestino, onde as populações se ressentiam dos efeitos das secas e esperavam por ações do Governo, sendo nesse núcleo que se deu o primeiro assentamento realizado pelo Estado, em um perímetro irrigado, destinado à colonização de agricultores sem terra no Vale do Submédio São Francisco.

Por volta de 1965, dois projetos piloto foram recomendados pela FAO: o de Bebedouro/PE e o de Mandacaru/BA. Em 1968, o Governo Federal instituiu o Grupo Executivo de Irrigação e Desenvolvimento Agrário (GEIDA) que, em 1970, lançava os delineamentos de uma política de irrigação para o Brasil, através do Programa Plurianual de Irrigação (PPI).

Além do Programa de Integração Nacional (PIN), de 1970, que contemplou o financiamento da primeira fase do Plano Nacional de Irrigação, em 1972, foi lançado o primeiro Plano Nacional de Desenvolvimento e, em 1979, o segundo PND.

Em 1986, foi criado o Programa de Irrigação do Nordeste (PROINE) e, em 1996, foi instituído, pelo Ministério da Agricultura, o Programa de Apoio ao Desenvolvimento da Fruticultura Irrigada no NE.

Somente em 2009, foi que o Ministério da Integração Nacional, através da CODEVASF, volta a ampliar a fronteira agrícola irrigada com a entrada em funcionamento de uma das cinco etapas do perímetro irrigado do Salitre, em Juazeiro (BA), nos mesmos moldes dos anteriormente implantados, com lotes destinados a empresas agrícolas e outros para agricultores familiares. 
Convém ressaltar que, ainda nos dias de hoje, no contexto de implantação de perímetros de irrigação no Vale do Submédio São Francisco, entre as características e as externalidades dessas políticas eminentemente setoriais, destacam-se: a persistência da centralização do processo decisório, fora das fronteiras território; a supervalorização da grande empresa agrícola, como vetor do desenvolvimento e a inviabilidade de processos que possibilitassem a formação de capital social dos agricultores familiares, como forma de favorecer um ambiente propício à governança territorial, baseada na participação democrática das representações desses produtores nas instâncias decisórias.

\section{Procedimentos metodológicos}

O estudo busca compreensão de fenômenos sociais a partir da localização, avaliação, síntese e informação em determinados períodos, sendo o tipo de pesquisa caracterizado como exploratória e descritiva, com abordagem qualitativa. $\mathrm{O}$ método utilizado foi o estudo de caso múltiplo a partir do qual se realizou uma análise comparativa entre duas experiências locais de adaptação de agricultores familiares em perímetros de irrigação no vale do Submédio São Francisco, sendo uma realizada mediante processos da política de colonização, no agropolo Petrolina-PE/Juazeiro-BA e outra realizada através de reassentamento populacional em municípios mais a jusante desse referido polo agrícola.

No que se refere ao levantamento e natureza dos dados, utilizouse a pesquisa documental com dados primários e secundários, além de bibliográfica, bem como entrevistas realizadas junto a técnicos de instituições públicas: CHESF e CODEVASF e de representantes de agricultores do perímetro de irrigação Pedra Branca, no município de Curaçá-BA.

Os processos de formação de capital social necessários à adaptação às territorialidades criadas pelos dos perímetros de irrigação, foram aqui considerados como atributos influenciados pela forma como ocorreram as ações dos agentes externos junto aos agricultores familiares, enquanto atores sociais nos dois contextos acima citados. A análise dos dados consubstanciou-se no confronto entre a teoria do capital social, na vertente neo-institucionalista de Durston $(1998,2000)$ e Abramovay (1998), relativa à possibilidade de sua formação e os registros obtidos nas fontes de dados, o que possibilitou a criação de um quadro qualitativamente configurado. 


\section{Apresentação e análise dos resultados}

\section{Caracterização do Vale do Submédio São Francisco}

A bacia do rio São Francisco abrange sete estados da federação, abrangendo biomas de cerrado e de caatinga. Com base no perfil longitudinal do rio e de seus principais afluentes, o Vale

do São Francisco é dividido em quatro grandes áreas: alto, médio, baixo e submédio, este último abrangendo áreas dos Estados de Pernambuco e da Bahia estendendo-se do município de Remanso (BA), até Paulo Afonso (BA).

Em termos médios, a precipitação anual chega a $350 \mathrm{~mm}$, com temperatura de $27^{\circ} \mathrm{C}$ anualmente, na região submédia, tendo evaporação da ordem de $3.000 \mathrm{~mm}$, típica do clima semiárido nordestino onde predomina a vegetação de caatinga em quase toda a área de 110.446 $\mathrm{km} 2$, cuja população é de aproximadamente dois milhões de habitantes (CODEVASF, 2010).

\section{A colonização agrícola no Submédio São Francisco e a inviabilidade da construção de capital social}

Segundo Silva (1973), a colonização implica no estabelecimento humano numa área e deve ser entendida como um fenômeno geopolítico, demográfico e econômico; segundo o qual, as áreas são ocupadas com objetivos sociopolíticos ou econômicos, podendo ser: espontânea, planejada ou dirigida e ter caráter privado ou estatal, porém, ocorrendo no caso brasileiro, sempre sob coordenação do Estado.

A promulgação do Estatuto da Terra, em 1964, respaldou um longo processo de colonização, na região Norte e Centro-Oeste, por meio da implantação de assentamentos de colonos oriundos do Sudoeste e do Sul, tendo sido os movimentos sociais duramente reprimidos na época. A opção do Governo militar se voltou à modernização da agricultura por meio de incremento ao uso de insumos químicos e mecânicos, deixando sem alteração a concentrada estrutura fundiária.

Na região do Vale do São Francisco, o surto modernizador da agricultura, segundo Andrade (1992), ocorreu em função das políticas públicas de irrigação do Governo no atendimento prioritário a grupos empresariais em detrimento dos agricultores familiares (colonos), 
desvinculando a função social da irrigação e facilitando a acumulação de capital, não alterando a estrutura de poder.

A primeira experiência de colonização, na região do Submédio, ocorrida no Núcleo Colonial Agroindustrial, os colonos foram selecionados ou indicados, desde que atendessem aos mecanismos normativos impostos, sob a responsabilidade de um funcionário do Ministério da Agricultura, o qual, além de selecionar, tinha poderes para excluir, substituir os colonos, além de viabilizar assistência; definir calendário agrícola e tudo mais que estivesse ligado à vida do Núcleo (ANDRADE, 1990).

O poder estatal que se expressava pela ação autoritária e coercitiva aniquilava as condições de organização autônoma dos trabalhadores exercendo controle sobre a força de trabalho que, naquele meio rural, destruiu e esvaziou a ação sindical. A inexperiência associativa dos colonos e o baixo nível de socialização, devido às condições de isolamento em que viviam, todos eram obrigados a ingressar como associado num modelo de "organização" baseado na cooperativa do Núcleo Colonial, cuja condicionante teve caráter autoritário e encontrou resistências e insatisfação entre os irrigantes, deixando a maioria deles em situação incômoda e desrespeitando um dos princípios essenciais do cooperativismo que é a adesão voluntária.

Diante disso, cabe refletir que, na fase inicial da política de colonização em perímetros irrigados no Submédio São Francisco, no que diz respeito à perspectiva de formação de capital social, a ação do Estado imprimiu um contexto de relações verticais, autoritárias, impróprias ao seu desenvolvimento.

Segundo Abramovay (1998), as agências estatais necessitam das comunidades como co-produtoras de seus resultados e não como seus clientes passivos. Da mesma forma, as comunidades necessitam de burocracias estatais, já que poucos serviços, nas sociedades contemporâneas, podem ser organizados num nível puramente local e sem o apoio dos conhecimentos e dos recursos que venham de Estados. Assim, deve haver sinergia entre Estado e sociedade para criação de um círculo virtuoso de mudança institucional, o que não se observou no contexto descrito acima.

A implantação dos perímetros públicos de irrigação, nos municípios de Juazeiro (BA) e Petrolina (PE), também não surgiu de forma organizada, por meio de uma demanda dos atores sociais inseridos naquele território. A escolha do espaço para construção não foi aleatória 
tendo sido realizada com base numa análise de suas potencialidades: o clima, solos e a proximidade da fonte hídrica (Rio São Francisco), bem como dos centros urbanos, que passariam a fornecer a infraestrutura de suporte à produção, à industrialização e à comercialização.

Foi implantada toda uma infraestrutura produtiva que, segundo Caldas (2006), reuniu cerca de 300 empresas agrícolas, muitas de outras regiões do país e mais de 2.500 agricultores familiares, na condição de colonos em torno de novos sistemas agrícolas baseados na intensificação do uso do solo, sob diversas formas de irrigação e na importação de grandes quantidades de insumos agroquímicos.

Essa política setorial teve, além de um objetivo econômico, o de desenvolver a região por meio da produção agrícola, aproveitando-se do potencial dos recursos naturais existentes, em especial a água do rio São Francisco; deveria ter também um objetivo social, consubstanciado na geração de empregos e distribuição de renda para evitando o êxodo rural.

Em ordem cronológica, foram construídos os perímetros de Bebedouro no ano de 1968, em Petrolina (PE), com 1.494 ha de área irrigada para colonos e 924 ha para empresas; Mandacaru, em 1971, na cidade de Juazeiro (BA), com 368 ha para colonos e 51 ha para empresas; Tourão, construído, em 1979, com 211 ha para colonos e 10.499 para empresas (agroindústria da cana-de-açúcar); Curaçá, também em Juazeiro (BA), instalado em 1980, com 1.964 ha para colonos e 2.490 ha para empresas; Maniçoba também do lado baiano, instalado em 1980, com 1.889 ha para colonização e 2.379 ha para empresas; Nilo Coelho instalado em 1984, em Petrolina (PE) com 11.062 ha para colonos, 9.194 ha para empresas e 660 ha para técnicos em ciências agrárias.

Nesses perímetros, após a seleção dos colonos, reproduziu-se a mesma lógica da participação compulsória em entidades associativas, como no Núcleo Colonial de Petrolândia (PE), sem que a vontade ou não de associar-se fosse colocada como opção. Um estudo realizado, em 1985, levantou, em meados da década de 80, que quase metade dos associados não chegava a se inteirar das ações desenvolvidas pela cooperativa ou pela CODEVASF. Não sabiam distinguir as atividades realizadas por uma ou por outra instituição. Constatou-se ainda que $14 \%$ deles julgavam a cooperativa era uma continuação da CODEVASF e 10\% eram incapazes de diferenciar a transação existente com "sua organização" e outros tipos de negócios (BNB, 1985). 
Outros dados levantados indicaram que $86,9 \%$ dos agricultores não sabiam quem indicou o gerente da cooperativa; $62 \%$ desconheciam os responsáveis pela escolha dos funcionários; $51 \%$ declaravam incapazes de saber de onde partem os planos de exploração agrícola e mais de $40 \%$ não tinham noção de como eram aprovados o balanço da organização. A pesquisa revelou ainda que predominava, entre os associados, a ideia de que o presidente e o gerente da cooperativa eram as pessoas de maior poder de decisão na sociedade, conforme $70 \%$ dos entrevistados.

Martins e Zats (1990) dividem o processo de criação e desenvolvimento de cooperativas em projetos públicos de irrigação em duas fases: 1. Fase inicial de implantação e 2. Fase de Emancipação. Para as autoras, ao estruturar cada perímetro sob os moldes administrativos de cooperativa, o Estado, por um lado, configurava uma imagem de modernidade em suas obras de intervenção na agricultura, aliando ao sistema de produção irrigada uma forma de poder de princípios autônomos, de inspiração democrática, assegurada pelo modelo cooperativista; e por outro, garantia o controle sobre o desenvolvimento da sociedade agrária, calcado na dependência de maciços investimentos nos projetos, nos privilégios e articulações das relações eminentemente paternalistas.

$\mathrm{O}$ traço mais marcante na primeira fase - de implantação das cooperativas, foi a intervenção do Estado na direção destas, com o caráter hierárquico de poder entre promotores e produtores, apesar de ter sido baseado num ideário de participação nas decisões, porém sem que tivesse havido capacitação dos colonos para autodireção e construção das condições para retirada do Governo.

A cooperativa assim estruturada, em região de forte tradição cultural nas relações de produção e de sobrevivência, dá-se maiores dificuldades de consolidação, uma vez que os associados não foram preparados para entender seu papel na organização e mesmo o papel desta, como lócus da comunidade de onde emanam as possíveis satisfações dos interesses coletivos.

Porém, se tivessem sido bem trabalhados pelos técnicos e agentes, em nível de consciência da posição de poder e potencialidade, poderiam reverter em motivação para romper com os limites impostos pela socialização baseada no trinômio: proprietário/feitor/trabalhador rural.

Sobre isto, Durston $(1998 ; 2000)$ afirma que, quando o capital social da comunidade local não existe, é altamente provável que tenha sido reprimido, no passado recente, e a remoção ou o enfraquecimento 
do clientelismo autoritário criam um clima favorável para o seu surgimento. Metodologias e técnicas para a valorização do capital social existentes possibilitam a sua construção de forma deliberada não como um produto secundário ou de experiência espontânea.

Ao estudar a construção de capital social comunitário num caso na Guatemala, o autor identifica que, no início da instalação do programa de desenvolvimento, a realidade da região era marcada pela carência de organizações, por um espírito individualista e por relações de clientelismo e dominação disseminadas em todas as comunidades, o que não eliminava nestas a existência de fatores considerados precursores do capital social. Neste contexto, a materialização desses potenciais se deveu às iniciativas do agente externo.

Na referida experiência de formação de capital social, o uso de metodologias participativas e a institucionalização de espaços participativos acompanharam todo o processo, com a intenção gradual de transferir o protagonismo do planejamento e da execução das ações do projeto para os beneficiários finais. Em primeiro lugar, os agentes externos investiram na capacitação, fortalecendo destrezas sociais, capacidades de diagnóstico, comunicação e planejamento e em segundo, oportunizaram espaços para que tais habilidades fossem executadas.

Nessa perspectiva, a fase inicial de implantação de cooperativas nos perímetros irrigados de Petrolina (PE) e Juazeiro (BA) caracterizou-se como imprópria ao intento de viabilizar o protagonismo por parte dos agricultores familiares, uma vez que desconsiderou as possibilidades de construção do capital social.

A segunda fase do processo de implantação de cooperativas nos perímetros de irrigação, o Estado buscou priorizar a recuperação financeira daquelas que estavam em desequilíbrio e investir na capacitação dos funcionários públicos, deixando adiadas as imprescindíveis ações de educação cooperativista do corpo social, focando no desempenho empresarial destas entidades, esperando que os colonos assimilassem os reflexos dos resultados, de modo que se ocupassem unicamente das responsabilidades da produção agrícola.

Segundo Martins e Zats (1990), deram-se os jogos de culpa, sendo atribuída a maior carga de responsabilidade ao colono, exatamente por sua incapacidade de assimilar os novos elementos requeridos pela produção irrigada e por sua rejeição tradicional à participação nos trabalhos associativos. 
Cabe ressaltar que um documento do Banco Mundial denominado "Impactos e Externalidades Sociais da Irrigação no Semiárido Brasileiro, de junho de 2003 (quase duas décadas depois), ainda deixa evidente essa perspectiva nos dias atuais: de que os colonos respondem pelas situações desfavoráveis nos perímetros irrigados. Nesse documento, pode-se extrair passagens como:

[...] a falta de programas adequados para conscientização, transferência de informação e tecnologias aos pequenos produtores foi um fator que levou a frustrações de produção e à marginalização dos produtores (BANCO MUNDIAL, 2003, p. 10).

Sobre o tipo adequado de colono a ser assentado e a necessidade de favorecer a reprodução do modelo empresarial:

É importante começar os assentamentos com pre-
sença de produtores empresariais, dando início ao
assentamento com a presença dos pequenos pro-
dutores familiares, quando os produtos/cluters
assim como os padrões tecnológicos e os mercados
já estiverem sido identificados e implementados
pelos grupos mais fortes. O desenvolvimento do
capital humano e a transferência de tecnologias são
os aspectos mais críticos. (BANCO MUNDIAL,
2003, p.11).

Tais constatações confirmam o caráter tradicional das políticas setoriais verticalizadas que vão na direção contrária do processo de desenvolvimento territorial o qual, segundo Tonneau e Vieira (2006), implica no esforço de subordinar o processo a objetivos sociais, buscando soluções economicamente viáveis e politicamente descentralizadas, cuja participação dos agricultores familiares deve ser processualmente construída.

Entre 1968 e 1980, foram criadas diversas cooperativas, porém a CODEVASF se esforçou para estimular a participação dos colonos com ações que visavam, inclusive, à criação de condições objetivas para, num futuro, realizarem a autogestão dos perímetros de irrigação. No entanto, entre 1980 e 1989, o modelo de associação aparece como alternativa de organização para substituir as cooperativas que não vinham trazendo resultados, sendo incentivada a criação, atribuindo-lhes a responsabilidade pela operação e manutenção dos sistemas de irrigação e 
pelos serviços de assistência técnica e extensão rural - ATER. A ideia de emancipação dos perímetros ressaltou-se como meta primordial da política da CODEVASF notadamente a partir de 1986.

Novos caminhos foram percorridos no sentido de firmar contratos de co-gestão com as organizações, já na condição de emancipadas. $\mathrm{E}$, ainda não satisfeita com os resultados globais dos perímetros, a CODEVASF, com apoio do Banco Mundial, impôs aos agricultores outro tipo de organização visando a alcançar maior eficiência econômica baseado no Distrito de Irrigação, como se a simples troca de modelos oferecesse soluções para realização dos objetivos básicos de desenvolvimento.

Entretanto, na criação dos Distritos de Irrigação, não houve preparação dos usuários, sendo que os funcionários da CODEVASF anunciavam sua instalação como uma ameaça ou castigo pelos conflitos que ocorriam entre as organizações nas atividades de gerência do perímetro. De outra forma, para os colonos, o Distrito de Irrigação apareceu mais como uma imposição da CODEVASF para solucionar seus problemas.

Quanto a esse contexto, o que a problemática da imposição de sucessivos modelos de organização aos agricultores traz, à baila, segundo Abramovay (1990), é que quando os indivíduos (no caso, os colonos) sentem que não existem alternativas ao autoritarismo ou ao desmando, será evidentemente maior a propensão a submeter-se verticalmente a estes poderes e a renunciar ao investimento em redes horizontais de cooperação, que são a base do capital social.

\section{A experiência dos agricultores do reassentamento de Itaparica}

Afora a realidade tratada até agora, acerca dos perímetros irrigados do agropolo Petrolina (PE) e Juazeiro (BA), cabe trazer, à baila, que outros perímetros públicos de irrigação entraram em funcionamento no Submédio São Francisco nos últimos anos do século XX, para o assentamento de famílias de agricultores atingidos na formação do lago da hidrelétrica de Itaparica, a cargo da Companhia Hidrelétrica do São Francisco - CHESF, o qual atingiu $834 \mathrm{Km}^{2}$ a cerca de $300 \mathrm{~km}$ a jusante da represa de Sobradinho (BA).

Nove perímetros de irrigação foram implantados, tanto nas margens do lago da referida hidrelétrica, quanto em áreas de municípios 
rio acima, sendo: Barreiras, Apolônio Sales e Icó Mandantes, em Petrolândia-PE; Manga de Baixo, em Belém do São Francisco-PE; Brígida, em Orocó-PE e Fulgêncio em Santa Maria da Boa Vista-PE, no lado esquerdo do rio, além dos perímetros Glória, em Glória-BA; Rodelas, no município de mesmo nome e Pedra Branca, entre Abaré e Curaçá-BA do lado direito do rio. Todos esses perímetros foram dotados de infraestruturas para moradia e serviços em 126 agrovilas, além de áreas agrícolas irrigadas que totalizaram 12.640 ha, as quais foram distribuídas para 3.330 famílias de agricultores em lotes individuais de 3,8 ha em média. (BANCO MUNDIAL, 2005).

Diferentemente do agropolo Petrolina (PE) - Juazeiro (BA), onde os agricultores familiares foram selecionados para enquadramento na política pública de colonização, o acesso dos agricultores aos recursos naturais e às infraestruturas produtivas dos perímetros de irrigação de Itaparica foi protagonizado por um Movimento Popular com base no Polo Sindical dos Trabalhadores Rurais do Submédio São Francisco, o qual mobilizou categorias de agricultores, proprietários de terras ou não, no transcorrer dos anos 1975 a 1990.

Tal movimento social unificou as estratégias para defender uma proposta de reassentamento das famílias atingidas pela construção da hidrelétrica, tratando-se, portanto, do resultado de uma mobilização coletiva articulada para conquista de direitos, antes não vislumbrados por outras populações atingidas, a exemplo do caso da hidrelétrica de Sobradinho, frente ao Estado.

A construção de uma nova identidade social, unificadora de interesses heterogêneos em face das ações de reassentamento, constituiu-se, na verdade, no resultado mais palpável de uma ação planejada dos agricultores, empreendidos por organizações sindicais atuantes na área e, nesse ambiente, emerge o campesinato como força social organizada, conquistando espaços importantes na redefinição das relações de poder. (FUNDAJ, 2006).

Porém, só a partir de 1995, quando pelo menos dois projetos: Brígida e Glória apresentavam certa regularidade nas atividades ligadas à exploração irrigada é que se instaura nova etapa do reassentamento, onde o tema: produção e seus desdobramentos passam a nortear as linhas de atuação dos órgãos governamentais e também dos sindicatos dos trabalhadores rurais - S.T.Rs. 
O processo organizacional dos agricultores, no entanto, não escapou da intervenção dos diversos agentes institucionais presentes ao contexto do reassentamento. Segundo Albuquerque (1999), a conquista da terra em Itaparica foi o fato que despertou os agricultores para outro tipo de poder distinto daquele do grande proprietário ao qual estavam submetidos e suas instituições são, agora, merecedoras de confiança. O Polo Sindical dos Trabalhadores Rurais do Submédio São Francisco, nesse contexto, chamou para si as discussões de cunho institucional até os dias atuais.

No entanto, com o propósito de ver os agricultores engajados em todas as questões de cunho coletivo frente às forças que a essas se opunham, mesmo no âmbito interno à categoria, quando, por exemplo, as tendências políticas partidárias e principalmente a forma de organização para gestão da produção, entre outras, que não congregassem o componente ideológico do Polo, incorreu em exclusão de indivíduos e grupos das suas discussões, fato confirmado na fala de um técnico:

Pode-se perceber que as decisões passam pelas mesmas pessoas. Como elas não têm experiência para decidir coletivamente a coisa fica assim: o que o presidente da cooperativa fala eles acatam ${ }^{6}$

A estratégia de manutenção de consenso do Polo Sindical ficou bastante evidente quando se deram os processos para constituição das primeiras cooperativas nos perímetros irrigados em operação. Nesse momento, foram definidos pelo Polo, os passos para fundação de várias associações consideradas pré-cooperativas por parte das lideranças sindicais, de forma a permitir um exercício rumo ao cooperativismo entre agricultores.

Entretanto, a exemplo do perímetro de Pedra Branca, em Curaçá-BA, a fundação da primeira associação teve claro objetivo de não permitir o surgimento de outras que não tivessem relação com a filosofia defendida pelo Polo Sindical, mantendo a unidade dos agricultores e as mesmas lideranças sindicais que estiveram à frente do processo de conquista do reassentamento.

Se de um lado, o Polo Sindical teve inegável contribuição para o processo de conquista da terra, por outro, ele não conseguiu, naquele

6 Entrevista com um técnico da ATER 
momento, distinguir os mecanismos de ação institucional, no qual a assessoria e apoio político às organizações deveriam favorecer a construção coletiva de estratégias visando a atingir objetivos comuns, através de processos participativos e democráticos.

Nesse contexto do processo organizacional, foi notória a presença da Igreja em alguns perímetros, sobretudo do lado da Bahia. A assessoria prestada por religiosos e assessores teve caráter complementar e objetivava ver os agricultores transformados em homens fraternos e solidários a partir dos vínculos entre a união dos homens com sua organização. Essa ação, porém, atuava no plano da subjetividade dos indivíduos, trazendo consigo um componente de resignação, notadamente na referência ao trabalhador enquanto "pequeno e pobre", na sua luta por dias melhores.

A assessoria da Igreja era contemporânea dos episódios em torno da luta pela terra em que, segundo Pandolffi (1986), a linguagem cristã era encontrada nas letras dos cânticos que eram divulgados durante as concentrações de trabalhadores, transparente a mensagem conscientizadora da união entre os pequenos para vencer suas dificuldades.

O trabalho da Igreja, assim, realizou-se ferindo a lógica da participação para conquista de interesses, uma vez que essa assessoria usa de uma tática para discutir a organização a partir dos apelos à união ressalvando o sentido de pequenez do trabalhador o qual não favorece a superação dos limites impostos pelas relações de poder arraigadas na vivência dos agricultores na perspectiva da construção do capital social.

Cabe ressaltar que, segundo Franco (2001), não é a virtude humana de um indivíduo que se soma a outras virtudes humanas de outros indivíduos para compor o estoque de capital social de uma sociedade e sim o padrão de organização e o modo de regulação adotados. Em outras palavras: o capital social não é função da "densidade superficial de santos”, quer dizer, do número de santos por metro quadrado que existem numa sociedade e sim do tipo de interação que se estabelece entre os pecadores.

Outros elementos vêm à tona constituindo-se como pressões externas para acelerar todo processo organizacional, no que tange à constituição de cooperativas no contexto de Itaparica, levados a cabo como estratégia pelo Estado visando a associá-los de modo a predeterminar sua eficiência ou sua capacidade de convivência com as regras do mercado e para terem acesso aos programas estatais. 
$\mathrm{Na}$ tentativa de descentralizar ações, o Estado, através da CODEVASF, buscou também transferir responsabilidades na gestão dos projetos de irrigação à maneira de como ocorreu nos perímetros do agropolo de Petrolina-PE e Juazeiro-BA, no bojo do processo para operacionalizar os sistemas de irrigação e viabilizar serviços como a assistência técnica aos agricultores reassentados, reproduzindo a postura em busca da emancipação dos perímetros irrigados.

Ao mesmo tempo, a representação dos agricultores, através do Polo Sindical dos Trabalhadores Rurais do Submédio São Francisco, visou a encaminhar a emancipação dos perímetros diferentemente do modo como foi realizado pela CODEVASF, apenas substituindo modelos de organização:

A proposta é assentada na constituição de uma rede de cooperativas singulares e centrais que a curto e médio prazos farão a administração da ATER, a operação e manutenção e da produção e comercialização, incluindo a instalação de agroindústrias. (SOUZA; BARROS, 1997, p. 21).

Para os agricultores, de forma geral, esse contexto se dá com naturalidade, haja vista ter sido legitimado por sua representação, porém isso ocorre como a reprodução do fato histórico dessa relação com o Estado: sem que os reais interessados, os agricultores familiares, pudessem avaliar e decidir por caminhos alternativos, de forma autônoma e democrática.

Assim, o processo organizativo dos perímetros de Itaparica foi encaminhado ainda colhendo os frutos da "luta pela terra", sob forte influência das lideranças sindicais, pelo Estado e, em parte pela Igreja, não viabilizou o cumprimento dos objetivos voltados à conquista da autopromoção a partir da construção de capital social, fazendo ocorrer a reprodução de relações autoritárias impróprias à participação dos agricultores para gestão coletiva de seus interesses na perspectiva territorial.

\section{Considerações Finais}

São raras as cooperativas que prestam algum serviço aos seus associados no âmbito dos perímetros de irrigação do vale do Submédio São Francisco nos dias atuais. Os registros constantes, nos relatórios da assistência técnica e extensão rural - ATER e nas entrevistas 
realizadas, dão conta de que outras alternativas estão sendo frequentemente encaminhadas, a exemplo do Grupo Manga Brasil, no perímetro de irrigação Curaçá e outras associações que mantêm integração com agoindústrias, porém mostrando entraves nas relações interpessoais e interorganizacionais.

Os distritos de irrigação, por força da lei e do histórico para sua constituição estão funcionando nos perímetros do agropolo Petrolina/ Juazeiro, no entanto, no contexto de Itaparica, ainda, trava-se sucessivos embates acerca do processo emancipatório entre os agricultores, através do Polo Sindical e a CODEVASF.

A pesquisa evidenciou que historicamente não ocorreu apoio aos processos organizacionais na perspectiva da formação de capital social no âmbito dos perímetros irrigados do Submédio São Francisco, cujo resultado é a fragilidade das relações horizontais, fruto de um projeto de desenvolvimento setorial excludente que privilegiou a eficiência econômica acima de qualquer outra dimensão, o que não coaduna com a perspectiva do desenvolvimento territorial sustentável.

No entanto, novas estratégias institucionais de desenvolvimento territorial vêm sendo colocadas em prática na região, implicando na revalorização de atores coletivos na percepção de possibilidades de inserção em processos decisórios e de governança, mediante processos participativos. Tais estratégias estão ocorrendo ainda sem grandes impactos, através das articulações promovidas pela política de desenvolvimento territorial do MDA, dado seu caráter processual, mas também devido às contradições existentes nas prerrogativas da gestão governamental, a qual incoerentemente mantém numa mesma região políticas de desenvolvimento completamente opostas; de um lado, o MDA, como já comentado e do outro, o Ministério da Integração Nacional mantendo o modelo setorial atrasado, porém legitimado politicamente por setores que, de modo histórico, lidam habilmente com o poder. 


\section{Referências}

ALBUQUERQUE, Gilton C.A. de. A Participação dos Agricultores familiares no Contexto do processo Organizacional: $\mathrm{O}$ caso do Projeto Pedra Branca - BA. Recife, 1999. Dissertação de Mestrado - CMARC/ UFRPE.

ANDRADE, Margarete C. Irrigação e Colonização: a prática dos pequenos produtores, o caso do projeto Mandacaru. Recife (PE), 1990. Dissertação (Mestrado em [Ciências Sociais]) - CCSA/UFPE.

ANDRADE, J. C. A bacia do São Francisco: geografia e vocação natural para o desenvolvimento. In: OFICINA do São Francisco. Recife: Documento do grupo de trabalho sobre desenvolvimento e Impactos Ambientais do IV Congresso Nordestino de Ecologia, 1992.

ABRAMOVAY, Ricardo. A Formação de Capital Social para o Desenvolvimento Local Sustentável. In: FÓRUM DE COOPERAÇÃO TÉCNICA, 2, 1998. São Luiz. [Anais...] São Luiz: CONTAG, 1998.

. O capital social dos territórios: repensando o desenvolvimento rural. Revista Economia Aplicada, v.4, n. 2, p. 379-397, abri./jun. 2000. . Representatividade e inovação. Paper Seminário Nacional de Desenvolvimento Rural Sustentável, Brasília: CONDRAF/MDA, 2005.

BANCO MUNDIAL. Impactos e Externalidades Sociais da Irrigação no Semiárido Brasileiro: Relatório para apresentação e debate no Ministério da Integração. Brasília, 2003.

. Memorial sobre o Reassentamento de Itaparica. In: FÓRUM TÉCNICO SOBRE REASSENTAMENTO DE POPULAÇÕES. 2, 2005, Bogotá, Colômbia. [Anais...], Bogotá, Colômbia, 2005.

BANCO DO NORDESTE DO BRASIL. Organização Cooperativa nos Projetos de Colonização do Vale do São Francisco. Relatório de pesquisa. Fortaleza (CE), 1985. 
BARROS, Edonice da Rocha. Arranjos Socioprodutivos da Agricultura Familiar e Adaptação a uma Dinâmica Territorial de Desenvolvimento: o caso dos Perímetros de Irrigação no Vale do São Francisco, Semiárido Brasileiro. Santa Catarina, SC, Tese (Doutorado em Desenvolvimento Rural e Sustentável) - UFSC. 2007.

BARROS, E.; TONNEAU J. P. Transformações ocorridas na agricultura familiar numa região afetada pela barragem: um caso estudo no Submédio São Francisco, no Nordeste do Brasil. In: XI CONGRESSO MUNDIAL DE SOCIOLOGIA RURAL, 11, 2004, Trondheim, Norway= Noruega Anais... Noruega, 2004. Disponível em < http://www.irsa-world.org/prior/ XI/papers/groups.html>. Acesso em: 10 dez. 2010.

BEDUCHI FILHO, L. C.; ABRAMOVAY, R. Desafios para o desenvolvimento das regiões rurais, 2004. Disponível em <http://www.abramovay. pro.br/artigos_cientificos/2004/Beduschi_Abramovay.pdf >. Acesso em: 05 jan 2011.

CALDAS, Alcides Santos dos. Globalização em Territórios Periféricos: os sistemas Produtivos Rurais da Bahia e da Galícia. Salvador (BA): UNIFACS, 2006.

CODEVASF - Companhia de Desenvolvimento dos Vales do São Francisco e do Paranaíba - /GEEPI - Grupo de Integração de Política Econômica e Ambiental. Relatório mensal de monitoria. Petrolina (PE), 1996.

Inventário de Projetos. 3. ed. Brasília-DF. 1999. Documento.

Almanaque do Vale do São Francisco. Brasília: CODEVASF, 2001.

COELHO NETO, A. S. Da região ao território: pensando a territorialidade no semiárido baiano. In: ENCONTRO NACIONAL DA ANPEGE, 8, 2009, Curitiba. Anais... Curitiba: ANPEGE/UFPR, 2009.

DURSTON, Jonh. Construção do Capital Social em comunidades rurais (Onde ele não existe). Santiago - Chile: CEPAL, 1998.

2000.

Qué es el capital social comunitário? Santiago - Chile: CEPAL, 
FRANCO, Augusto de. Capital Social: Leituras de Tocqueville, Jacobs, Putnam, Fukuyama, Maturana, Castells e Levy. Instituto de Política Milenium, 2001.

FUNDAJ. Reassentamento Rural em Itaparica: $2^{\circ}$ relatório de avaliação anual (1987 /1996). Disponível em: <http://www.fundaj.gov.br/geral/ textos\%20online/economia/rosa\%20amorim\%20org

pdp> Acesso em: 02 jul. 2009.

MARTINS, Leila; ZATS, Inês. Estudo sobre a participação do Sistema Cooperativo em Projetos de Irrigação no Nordeste. Brasília: MARA, 1990.

NOVAES, Ricardo C. Investimento em Capital Social como Estratégia para Construção da Sustentabilidade local: apontamentos teórico-metodológicos. In: ENGEMA. 1, 2005. Rio de Janeiro (RJ), Anais... Rio de Janeiro, 2005.

PANDOLFFI, Maria L. Na Margem do Lago: um estudo sobre o sindicalismo rural. Recife, 1986. Dissertação de Mestrado (Sociologia) - UFPE.

SABOURIN, E. Viabilidade da agricultura familiar nordestina e globalização: mitos e desafios. Revista Política \& Trabalho, v.6, p. 25-39, set. 2000.

SCHNEIDER, Sergio. Agricultura Familiar e Desenvolvimento Rural Endógeno: elementos teóricos em um estudo de caso. In: FROEHLICH, Marcos.; DIESEL, Vivian (Org) Desenvolvimento Rural: tendências e debates contemporâneos. Ijuí: [s.n.], 2006.

SOBRINHO, J. S. de. Desenvolvimento no Vale do São Francisco: uma análise crítica. In: ENCONTRO NACIONAL DE GEOGRAFIA AGRÁRIA, 19, 2009, São Paulo, Anais... 2009. Disponível em <http:// www.geografia.fflch.usp.br/inferior/laboratorios/agraria/Anais\%20 XIXENGA/artigos/Sobrinho_JS.pdf>, Acesso em: 27 nov. 2010.

SOUZA, C.; BARROS, J. Autogestão se faz botando a mão na massa: relatório. Petrolândia: Polo Sindical dos Trabalhadores rurais do Submédio São Francisco, 1997. 